\title{
Cuerpo y bolero. La Lupe: una aproximación en clave de artefacto cultural
}

Celiner de Jesús Ascanio Barrios

Universidad de las Américas, Quito, Ecuador celinerascaniobarrios@gmail.com

Christian Paul Chasi Escobar

Universidad de las Américas, Quito, Ecuador christian.chasi@udla.edu.ec

Recepción: septiembre 2019. Aceptación: diciembre 2019.

\section{Resumen}

El cuerpo es el lugar en donde se inscribe la subjetividad. No existe subjetividad sin cuerpo. Más allá de las teorías políticas, los estudios sobre esta categoría se abren también a perspectivas que lo conectan con la vida y el deseo. El cuerpo erótico constituye así una deriva que dialoga con las Políticas del Afecto y los Estudios Culturales. Nuestro trabajo parte de un fenómeno, pensado como "artefacto cultural", que se origina en la música y estalla hacia otros campos generando una productividad. El objetivo del presente artículo es analizar categorías como cuerpo y erotismo y su relación con el bolero, a partir de una figura que constituye una "personalidad de excepción" en quien vida y obra se mezclan para dar lugar a un artefacto cultural: La Lupe. Nuestro corpus está conformado por formatos que permitirán leer esta productividad que representa La Lupe en Latinoamérica durante el siglo XX. Partiremos de las propuestas teóricas de Roger Dadoun sobre erotismo, cuerpo y deseo, y de las discusiones sobre "originalidad" de Gilles Deleuze, en diálogo con diferentes lecturas sobre el bolero que permitirán comprender las categorías anteriores, tomando en cuenta la especificidad que tienen dentro del imaginario latinoamericano.

Palabras clave: artefacto cultural, bolero, erotismo, cuerpo, La Lupe 


\title{
Corpo e bolero. La Lupe: uma abordagem em termos de artefato cultural
}

\section{Resumo}

O corpo é o lugar onde se inscreve a subjetividade. Não há subjetividade sem corpo. Além das teorias políticas, os estudos sobre esta categoria também se abrem para perspectivas que a conectam com a vida e o desejo. 0 corpo erótico constitui, assim, um desvio que dialoga com as Políticas do Afeto e os Estudos Culturais. 0 nosso trabalho baseia-se num fenômeno, pensado como "artefato cultural", que se origina na música e se estende a outros campos, gerando produtividade. 0 objetivo deste artigo é analisar categorias como corpo e erotismo e a sua relação com o bolero, a partir de uma figura que constitui uma "personalidade excepcional" na qual a vida e o trabalho se misturam para dar origem a um artefato cultural: La Lupe. 0 nosso corpus é composto por formatos que permitirão ler essa produtividade que La Lupe representa na América Latina durante o século XX. Partimos das propostas teóricas de Roger Dadoun sobre erotismo, corpo e desejo, e das discussões sobre "originalidade" de Gilles Deleuze, em diálogo com diferentes leituras sobre o bolero que nos permitirão entender as categorias anteriores, levando em conta a especificidade que elas adquirem dentro do imaginário latino-americano.

Palavras-chave: artefato cultural, bolero, erotismo, corpo, La Lupe

\section{Body and Bolero. La Lupe: A Cultural Artifact Approach}

\begin{abstract}
The body is the place where subjectivity is inscribed. There is no subjectivity without a body. Beyond political theories, studies on this category also open to perspectives that connect it with life and desire. The erotic body thus constitutes a drift that dialogues with the Policies of Affection and Cultural Studies. Our work is based on a phenomenon, thought of as "cultural artifact", which originates in music and explodes into other fields of thought, generating productivity. The objective of this article is to analyze categories such as body and eroticism and their relationship with the bolero, based on a figure that constitutes an "exceptional personality" in which life and work are mixed to give rise to a cultural artifact: La Lupe. Our corpus is made up of formats that will allow you to read this productivity that La Lupe represents in Latin America during the 20th century. We will start with the theoretical proposals of Roger Dadoun on
\end{abstract}


eroticism, body and desire, and the discussions on "originality" by Gilles Deleuze, in dialogue with different readings on the bolero that will allow us to understand the previous categories, taking into account the specificity they have within the Latin American imaginary.

Keywords: Cultural artifact, bolero, eroticism, body, La Lupe

\section{I}

Lupe Victoria Yolí Raymond ${ }^{1}$ nace en Cuba (1939), en un pequeño pueblo de Santiago, llamado San Pedrito. Maestra de escuela y luego cantante, comienza su carrera cuando gana un concurso sorprendiendo a la ya famosa Olga Guillot. Años más tarde, la bolerista recordaría que aconsejó a la naciente cantante buscar su propio estilo, "su personalidad". Consejo que la joven, al parecer, siguió para perderse entre el personaje de la diva y su propia vida. Más adelante, con el trío Tropicuba (fundado en 1959 junto a su primer esposo) inicia su faceta más pública. La singularidad de su voz, la fuerza de su interpretación y los rumores de violencia e infidelidades, le generan una fama no siempre vista con agrado por el recién instaurado régimen cubano. Dispuesta a conservar su estilo parte a México y luego a Nueva York, donde Mongo Santamaría y Tito Puente coincidirían sobre el talento de la cubana. ${ }^{2}$ Desde entonces La Lupe será conocida como The queen of latin soul.

Su particularísimo modo de presentarse en escena, el desenfreno, los gritos, los golpes a los músicos, además de sus declaraciones espontáneas y sin tapujos, alimentarán las especulaciones acerca del uso de alcohol y drogas. Porque ante el enigma no queda sino especular, es decir, "hablar de lo que (no) se sabe [y] quizá a eso se deba la enorme potencia de la afectación -interpelación al afecto- que acompaña al "caso" [excepcional] desde el momento primero de su establecimiento: su espectacularidad; y por ende, disposición a ser "mercadeado" (Cróquer, 2012, p. 93). Y es que, dentro del imaginario latinoamericano y caribeño, el relato de La Lupe mezcla la biografía, la anécdota, la especulación y el espectáculo musical. De manera que, como relato, su vida privada se encuentra con su representación pública, generando un espacio caracterizado por contradicciones en cuanto a una "verdad" de su vida.

\footnotetext{
${ }^{1}$ Los datos sobre su biografía fueron extraídos del documental La Lupe Queen Of Latin Soul (Full Documentary). Recuperado en: https://www.youtube.com/watch?v=UB_bIHCbeC8\&feature=youtu.be

${ }^{2}$ Con dos discos fundamentales: Mongo introduces La Lupe, de 1963, producido por Mongo Santamaría, y The King Swings, the Exciting Lupe Sings, de 1965, producido por Tito Puente.
} 
Así, después de su éxito como solista durante la década de los setenta y su declive en los ochenta, Lupe Victoria Yolí Raymond, alejada definitivamente de la santería, aparece en otro escenario y con otro público, ahora en la década de los noventa: una iglesia cristiana. Éxitos como La Tirana y Fiebre han sido cambiados por cantos de alabanzas, pero su voz, su intensidad y cierto excedente de los movimientos que la caracterizaron años atrás, permanecen. Aunque su rostro ya no fija el maquillaje, sus manos lo siguen limpiando como cuando cantaba en vivo Cualquiera. Si bien sus vestidos largos ya no asoman la piel, sí se saca los anteojos cuando comienza a cantar. El escenario sigue siendo suyo cuando cuenta la historia de su vida y también cuando lo llena con su cuerpo musical. Aun en la iglesia y con vestidos largos, La Lupe guarda un resto de goce que se evidencia en cierta productividad que no puede ser captada del todo por quienes la observan y escuchan a lo largo de su vida. Por productividad ${ }^{3}$ se comprende, en el caso de La Lupe, lo que de ella puede leerse o mantenerse como enigma a partir de su presencia como cuerpo, pero también como texto en el que pueden percibirse indicios de una vida que se entrecruza con el personaje del espectáculo. Es precisamente esta productividad la que genera una multiplicidad que se despliega, ya sea a través de sus conciertos, entrevistas, canciones, fotografías y también películas, obras de teatro, novelas y toda la ficción que se generó sobre su vida dentro y fuera de la industria cultural. ${ }^{4}$ ¿Cómo partir de la música para pensar categorías como cuerpo, erotismo y cultura cuando ya se ha articulado un discurso en torno a La Lupe?

Una aproximación a La Lupe cuestiona toda reducción. Las categorías que, casi siempre, son útiles para definir ciertos casos, en este resultan "naturalmente" deficientes: cantante, diva, mito, predicadora... Las particularidades de este objeto permiten abordarlo como un artefacto cultural que, según Luis Miguel Isava (2009): “'pone en funcionamiento' las redes de significación que lo hacen posible y lo justifican, pero al mismo tiempo las patentizan al escenificarlas en una suerte de inscripción significante

\footnotetext{
${ }^{3}$ Esta noción de productividad parte de la propuesta que Julia Kristeva hiciera en el capítulo "La productividad llamada texto", incluido en su libro Lo verosímil, de 1970. Allí Kristeva considera que el texto no solo constituye un producto acabado y dispuesto para el consumo, sino que puede ser concebido, desde su origen y fuera del círculo de la mercancía, como un acto. Es decir, el texto funcionaría como un artefacto en permanente reactualización que abre múltiples posibilidades de lectura. Si bien Kristeva pensó en este capítulo sobre el texto literario, en nuestro caso hemos expandido su propuesta hacia una noción de texto muy relacionada con la semiótica que lo asume como un conjunto de signos susceptible de ser leído, más allá de la palabra.

${ }^{4}$ Algunas de las obras producidas a partir de La Lupe, son: películas (La mala, 2009), novelas que la incluyen como personaje (Isla de los amores infinitos, de Daína Chaviano, 2006 y Tres tristes tigres, de Guillermo Cabrera Infante, 1965), biografías (La Lupe, la leyenda, de Carmen Mirabal, 2012 y Con el diablo en el cuerpo, de Rafael Darío Durán, 2008), artículo académico (Una genealogía feminista de la salsa: La India, La Lupe y Celia, de Frances R. Aparicio), entre otras.
} 
susceptible de ser leída, analizada, interpretada, (re)pensada" (p. 448). En este sentido, el artefacto cultural "La Lupe", requiere una mirada que lo ubique más allá de su definición naturalizada para pensarlo como instrumento conceptual en permanente productividad, no solo por lo que representó para el espectáculo y la cultura latinoamericana y caribeña, sino por lo que su lectura sigue produciendo:

Este proceso de "naturalización" del artefacto cultural tiende a verlo (ya no leerlo) como un "hecho" desde siempre comprendido. Sin embargo, un leve desplazamiento basta para poner de manifiesto su carácter de artefacto cultural, íntimamente vinculado con su artificialidady, con esta, su espesor significante (Isava, 2009, p. 449).

Es precisamente la productividad del artefacto cultural lo que permite resignificar la singularidad de La Lupe, más allá de la naturalización del discurso de la diva caribeña que la ha caracterizado. De manera que pensar su figura como artefacto cultural obliga a una relectura, pues una mirada que no se mueva a la velocidad de su objeto, o a una velocidad aproximada, no resulta del todo útil. Toda maniobra leve, todo pequeño giro queda descartado. Así, releer al personaje implica pensarlo dentro del discurso cultural, pero también para considerar su existencia más allá de este, es decir, atendiendo a los aspectos que han quedado obnubilados por el relato de la diva caribeña, caracterizado por lo anecdótico y su naturalización. Es precisamente esto último lo que permite hablar de una productividad que genera nuevos modos de aproximación en los que el artefacto cultural da las "señas" para su lectura. Una productividad que, además, difumina los límites entre su vida y su obra:

Una productividad donde lo "Real" de la vida del "creador" (la dimensión física de su cuerpo y las pulsiones que lo atraviesan) deviene indiscernible del producto de "su trabajo creativo"; y donde esa obscena imposibilidad de discernir se hace pública [...]. Una productividad que, además, obra: produce, genera, libera, crea (Cróquer, 2012, p. 93).

Cuando el discurso trata de asir lo incapturable lo que genera es una construcción cuya potencia original queda reducida a una síntesis necesaria a la cultura y, en el caso de La Lupe, a la industria cultural, siendo esta última la que define cómo los productos que crea -y que a su vez la conforman-, permanecen en el centro, en lo pliegues, en los márgenes o fuera de esta. A la industria cultural le interesa afianzar lo que es La Lupe, y, por otra parte, explotar lo que fue. En el primer caso, para vender; en el segundo 
para redimir. Estas negociaciones construyen y apuntalan un discurso en el que Lupe Victoria Yolí Raymond desaparece para afianzar un interés: conservar y modelar al personaje La Lupe. Sin embargo, hay un espacio dentro de este personaje en el que permanece un excedente que no permite a los discursos ocultar del todo a la persona. Es en este espacio en donde se configura la noción personaje de excepción ${ }^{5}$ que, en La Lupe, fusiona la vida con el discurso que se genera alrededor de ella como diva caribeña. Esto, a partir de un género como el bolero que es:

[A]l mismo tiempo tan general y tan aferradamente pegado a la circunstancia vital de quien lo adopta, que, respondiendo a la vez a lo que ocurre siempre a todos y a lo que sólo le ocurre a cada hombre en su particularidad, [provoca] el movimiento espontáneo de identificación por medio del cual ese sujeto encuentra su persona, la máscara que lo confirma en su papel de enamorado, sujeto sujetado y respaldado por una trama simbólica sancionada por la lengua y la cultura a la que pertenece" (Castillo, 1990, p. 24).

Ese lugar entre lo real vital y el discurso que es el bolero, es el que encarna en La Lupe, en su carácter movedizo, en esa personalidad inasible que la coloca en un espacio siempre otro.

\section{II}

La Guerra Fría es un acontecimiento que asoma en todos los eventos de la vida cotidiana. Los años 50 presencian el ascenso al poder de Fidel Castro en una isla a pocas millas de Miami. La historia de Cuba, que no se dejará de contar y versionar, agarra al mundo desprevenido. En Sierra Maestra las guerrillas que amenazan y en la Habana la rumba, la tumba, el danzón y el bolero... En ese ambiente La Lupe comienza su andar, que es de pies descalzos. El bolero se acurruca en la voz de la Yiyiyi y será ese mestizo sospechoso, que aglutina desde géneros literarios hasta derivaciones de ritmos afro, ${ }^{6}$ el que encarnará en su figura. Es precisamente la narrativa

\footnotetext{
${ }^{5}$ Para Eleonora Cróquer Pedrón (2012), la personalidad de excepción se caracteriza por ser aquella que "no funda ni instaura personalidad alguna. La desborda, más bien. La desquicia" (p. 92), porque se inscribe, agrega, "en una línea de tiempo que le corresponde, más bien, en tanto que una pesada y escandalosa 'excepción': se manifiesta, materialmente [...] como un 'caso'. Fenómeno 'anormal' donde los haya, que no deja de hacer causa de deseo en el investigador [...]. La paradójica incertidumbre frente a la evidencia es, quizá, el rasgo más desconcertante de un 'caso'” (pp. 92-93). Es precisamente la excepcionalidad de La Lupe la que genera una incertidumbre que abre la puerta a su relectura como artefacto cultural, incluso en esta época.

${ }^{6}$ Para Rafael Castillo Zapata (1991): “En un proceso de organización simbólica que no está muy lejos
} 
que se construye sobre este género musical la que recibirá a la cantante en cuerpo y voz porque, además, el bolero es también un tipo de discurso (Lara, 2001, p. 25), es decir, la conformación de un relato que construye unas determinadas subjetividades latinoamericanas de la época (años sesenta, setenta y ochenta), a la vez que se nutre de estas y pone a circular un imaginario del sentir:

La educación sentimental que supone esta música en sus lugares de origen -las islas de Cuba y Puerto Rico y México- moldean las relaciones amorosas, y conmueven, elevando el alma y haciéndola avergonzarse de la ruindad cotidiana. Esta insurrección romántica en clave popular y con ritmo, abrió las compuertas para cantar las penas o los placeres del amor, en un minibanquete de a dos, donde lo imposible se mezcla con lo real. Al mismo tiempo se comunican fragmentos de discursos culturales, formas de vivir el cuerpo, y los sentidos y los sentimientos (Zavala, 1995, p. 105).

La educación sentimental a la que se refiere Iris Zavala es el resultado de esa narrativa que pone en circulación el bolero. Un relato caracterizado por la idea romántica del amor que lleva las marcas de un sentir en el cuerpo, "una escritura mediante la cual el cuerpo deja su rastro en el lenguaje" (p. 106). El bolero es un género de la pasión que se expresa a través de una narrativa conformada por el canto, la música y el relato acerca del amor y la pasión. Como discurso, forma vínculos sociales (Zavala, 1995, p. 104), por lo que a partir de la entrada del bolero en la industria del entretenimiento, se establece una interacción y un intercambio dirigidos por un discurso amoroso que interpela a los sujetos que pertenecen a este imaginario y que nutre la narrativa del bolero; esto es, que representa modos de percibir, sentir y relacionarse afectivamente.

El bolero responde a un momento histórico en el que aparecen los primeros aspectos de la Modernidad y en el que las tecnologías para el entretenimiento no se limitan a administrar el ocio, sino que además proponen

del movimiento de la cortezia medieval, de la prodigiosa tarea colectiva -juglaresca y trovadorescade registrar un código estricto de la dinámica amorosa del hombre de los siglos XII y XIII, el bolero también puede ser considerado como el repertorio, labrado también colectivamente, de las hebras simbólicas maestras por entre las cuales se levantan los diseños de las diversas situaciones en que se ven envueltos los hombres enamorados de nuestro continente. Y así como la cortezia regularizó ceremonialmente el amor, determinando papeles y actitudes, las fórmulas expresivas y tácticas retóricas, los modos y procedimientos de los que podía y debía servirse enamorado de la Provenza meridional a la hora de ordenar y dirigir su conducta en las contiendas del amor, así me parece ver al bolero, en pleno siglo XX, y en este, a su manera, Mediodía del Caribe Hispano, en esta Occitania tropical de alianza africana y española, el resultado equivalente de ordenación simbólica comunitaria de la experiencia amorosa" (pp. 18-19). 
nuevas formas del sentir. Subjetividades y bolero -en un complejo intercambio- producen un relato amoroso afectado por la dialéctica autor, intérprete y escucha. Todo esto conducido por una incipiente industria cultural que interactúa con lo que Jesús Martín Barbero (1991) denominó "fidelidades primordiales":

[...] la memoria colectiva está incorporada a lo social por medio de una cultura oral donde la adquisición y difusión de lo leído corresponde al acto de escuchar. Esto, en el caso que estudiamos, es un modo de comprender la mediación dada entre las emociones que corresponden a la sonoridad de la música y los argumentos de sus letras, con toda la mitología popular de la canción y del ídolo que refuerzan la identidad de un conglomerado que virtualmente es susceptible y activo, en la medida en que accede a sus bienes simbólicos (p. 115).

Es este intercambio entre industria cultural e imaginario popular del sentir el que legitima el discurso amoroso del bolero como bien cultural, dotándolo de un repertorio en el que el "apasionamiento" actúa a manera de péndulo entre la posesión y la falta -del ser amado, claro-. ${ }^{7}$ Así, el discurso del bolero, que se establece entre la industria cultural, el intérprete y el escucha (el autor tiene aquí una función un poco más silente que en el caso de la literatura, por ejemplo), genera una red de intercambio subjetivo en el que se fusionan lo afectivo y la economía del entretenimiento. Esta dinámica hace pensar el bolero como una especie de "testimonio del impacto anímico" (Castillo, 1990, p. 12); es decir, un relato que habla de la experiencia individual y a la vez colectiva del amor en Latinoamérica, mediado por un mercado que descubre al intérprete, distribuye su producción y la vende.

Consolidada esta mediación entre subjetividad amorosa y circulación de la industria cultural, los aparatos de canonización empiezan a hacer un trabajo concentrado tanto en discriminar como en integrar, y, sobre todo, en "relatar oficialmente" unas afinidades. ${ }^{8}$ Esta estrategia de la industria cultural del bolero -la de no agotar subjetividades- termina por crear una

\footnotetext{
${ }^{7}$ El "ser amado", que no se reduce al amante o al amado del diálogo Platónico. Los hay también, y legítimamente, los relacionados a los nacionalismos, las adicciones o aquellos que destacan añoranzas específicas: En mi viejo San Juan (Javier Solis), Licor bendito (Julio Jaramillo), Arroyito de mi casa (Bola de Nieve).

${ }^{8}$ Graciela Montaldo en su libro de 2001, Teoría Crítica, teoría cultural, señala que "el canon es la forma en que se arma [...] el paradigma estético de una época" (p. 74). Agrega también que "el canon como ley escrita, no intenta sino homogeneizar gustos y producción estética. Por ello mismo es un elemento de regulación cultural fuerte (p. 74). Es precisamente esta característica de regulación del canon la que determina qué queda dentro, fuera o en los pliegues.
} 
serie de cánones hegemónicos que, paradójicamente, son visibles gracias a quienes circulan por los márgenes, es decir, aquellos que no pueden integrarlo, pero que, finalmente, terminan por dibujar la línea que encierra a los "elegidos". Esta labor de canonización es, hasta cierto punto, tarea fácil, pues sin importar sus adscripciones en la lista de elegidos constará, con más o con menos: Leo Marini, Los Panchos, Celia Cruz, Daniel Santos, Felipe Pirela, Toña la negra, Lucho Gatica, Agustín Lara... De este ejercicio se puede notar que algunos quedan fuera del canon por razones -aunque está claro que no hay relación entre canon y razón-, políticas, históricas o éticas. Algunos ejemplos: por razones políticas, Bola de Nieve o Jorge Sepúlveda; por venir de géneros distintos al bolero tradicional, Nat King Cole o Javier Solís; por no pertenecer a la época de oro: Chucho Avellanet o Café Quijano; por encarnar al anti héroe, Julio Jaramillo, o la tragedia, La Freddy o Guty Cárdenas, entre otros.

Dentro de la formación del canon que se estuviera estableciendo en la época de mayor difusión del bolero (que no la época de oro), La Lupe se presenta como un caso Raro. Intérprete que no llegó a la exclusividad requerida para ser considerada bolerista, es recordada, sobre todo, por sus aportes al género. ${ }^{9}$ Una figura en quien la ficción bolerística (la trama) se mezcla con la vivencia del cuerpo y en quien se inscribe el testimonio del esplendor final del bolero. Su "originalidad" desborda los estereotipos de la época para producir:

[...] una poderosa y solitaria Figura que desborda toda forma explicable: emite resplandecientes trazos expresivos que señalan la obstinación de un pensamiento sin imágenes, de una pregunta sin respuesta, de una lógica extrema y sin racionalidad... [los originales son] figuras de vida y de saber, conocen algo inexpresable, experimentan algo insondable" (Deleuze, 2009, párr. 24).

Y, agregamos una más de sus poderosas rarezas: entran y salen del canon, permanecen a través del tiempo y producen relatos enigmáticos que los ubican en zonas marginales, pero protagonistas de la(s) cultura(s). ¿Qué hace que La Lupe sea habitante permanente de estos márgenes?

\footnotetext{
${ }^{9}$ La Lupe inaugura la figura de la Femme Fatal dentro de la mitología del bolero, además de exhibir un divismo exótico bien aprovechado por el mercado la artista desafía al discurso amoroso, "afeando", a propósito, el canto.
} 
Más allá del papel de La Lupe como intérprete, su figura y su voz encarnan el bolero, ya no desde el estereotipo de amante ensoñada y pasiva que espera por el ser amado, sino como protagonista que, a través de la música, "abre espacio a un juego erótico, [entremezclando] el valor estético del cuerpo con la naturaleza corporal del lenguaje" (Zabala, 1995, p. 106). De ahí que la experiencia de una subjetividad colectiva tenga lugar tanto en las letras de las canciones como en el espectáculo que la acompaña: conciertos, shows televisivos, entrevistas, imagen discográfica... La cantante no es solamente una intérprete, es también el cuerpo del bolero, aunque resignificado, porque si bien este, "es una escritura mediante la cual el cuerpo deja su rastro en el lenguaje" (p. 106), en el caso de La Lupe, será el cuerpo el que vaya de la mano con un lenguaje que expresa pasión.

En la cantante, el péndulo entre la falta y la posesión que caracteriza al género se desliza hacia un nuevo espacio transformado por una voz y un cuerpo que más bien encarnan el deseo mismo. La Lupe viene a cuestionar las artimañas caballerescas y a desenmascarar, con las mismas armas musicales, el amor romántico produciendo una ruptura marcada por el erotismo que "aunque exhibe, explora y teatraliza al cuerpo [...] no deja de acercarse a este como 'oscuro objeto de deseo' que dispone a tratar, atravesar, desmontar y explorar por todos los medios imaginables" (Dadoun, 2006, p. 23). Así, La Lupe canta el final del “encanto", canta-aúlla, el fin de una mentira. Para demostrarlo se despoja de sus maneras de dama y de su estola, encara la farsa, la denuncia:

De cierto modo la mujer no cantaba sus canciones, sino que las sufría, las gritaba, las lloraba, con una rabia contenida y las ofrendaba con una cómplice seducción (Posada, 2016, párr. 2).

En el escenario era un vendaval; poderosa e intensa, sobre todo cuando cantaba boleros (Posada, 2016, párr. 8).

Es entonces en esta cadencia y en este susurro es donde se alborota y da gritos, en este canto de amor, donde arremete violentamente en contra de sus músicos, como si fuesen instrumento de percusión. El bolero reafirma su rebelión y su libertad, marca su momento histórico y establece su originalidad en la unión de una vida con su obra. 


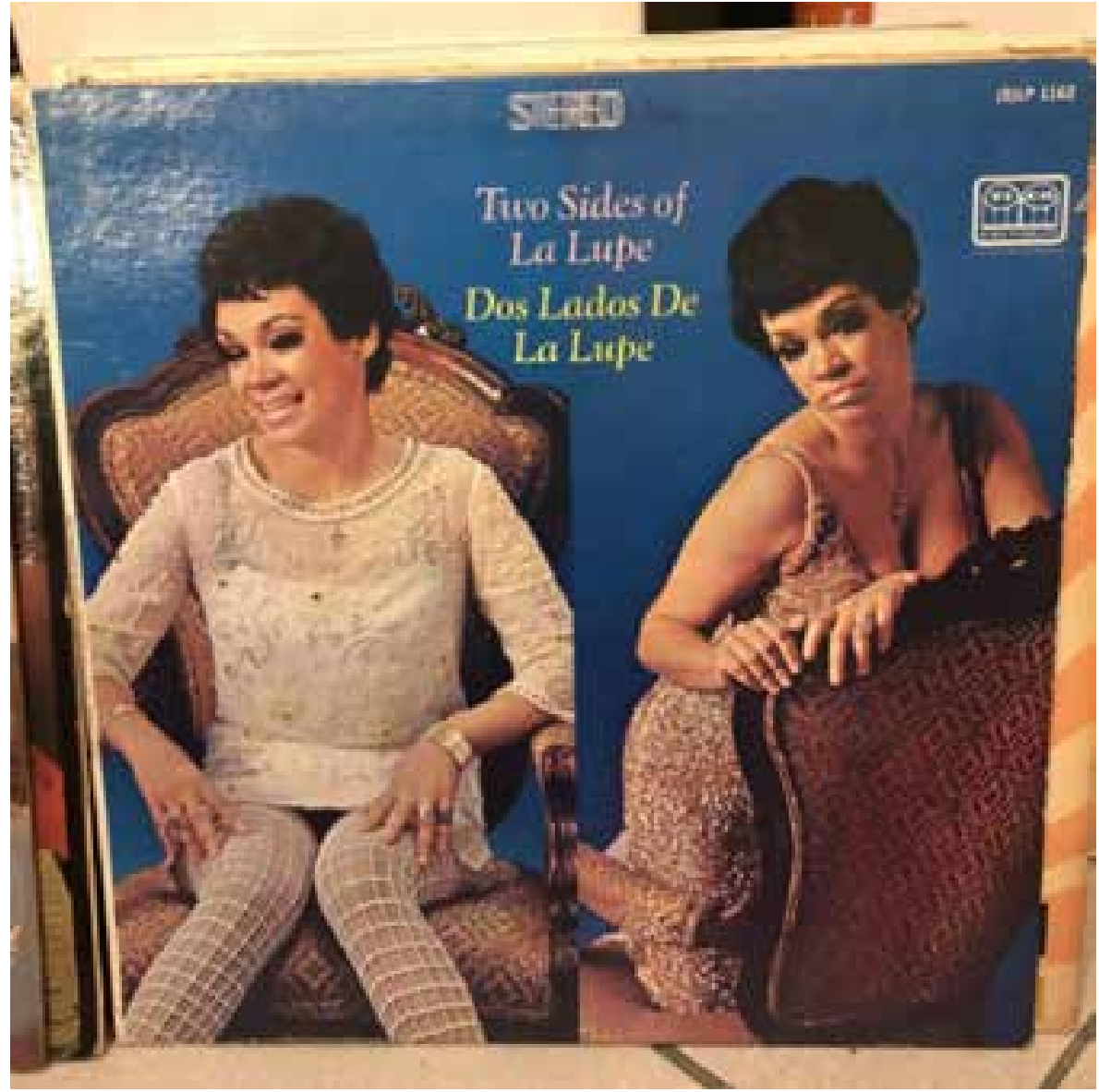

Imagen 1: Los dos lados de La Lupe. Recuperada de https://mion-records.berlin/wp-content/uplo ads/R-12085514-1528000082-3075.jpeg.jpg 


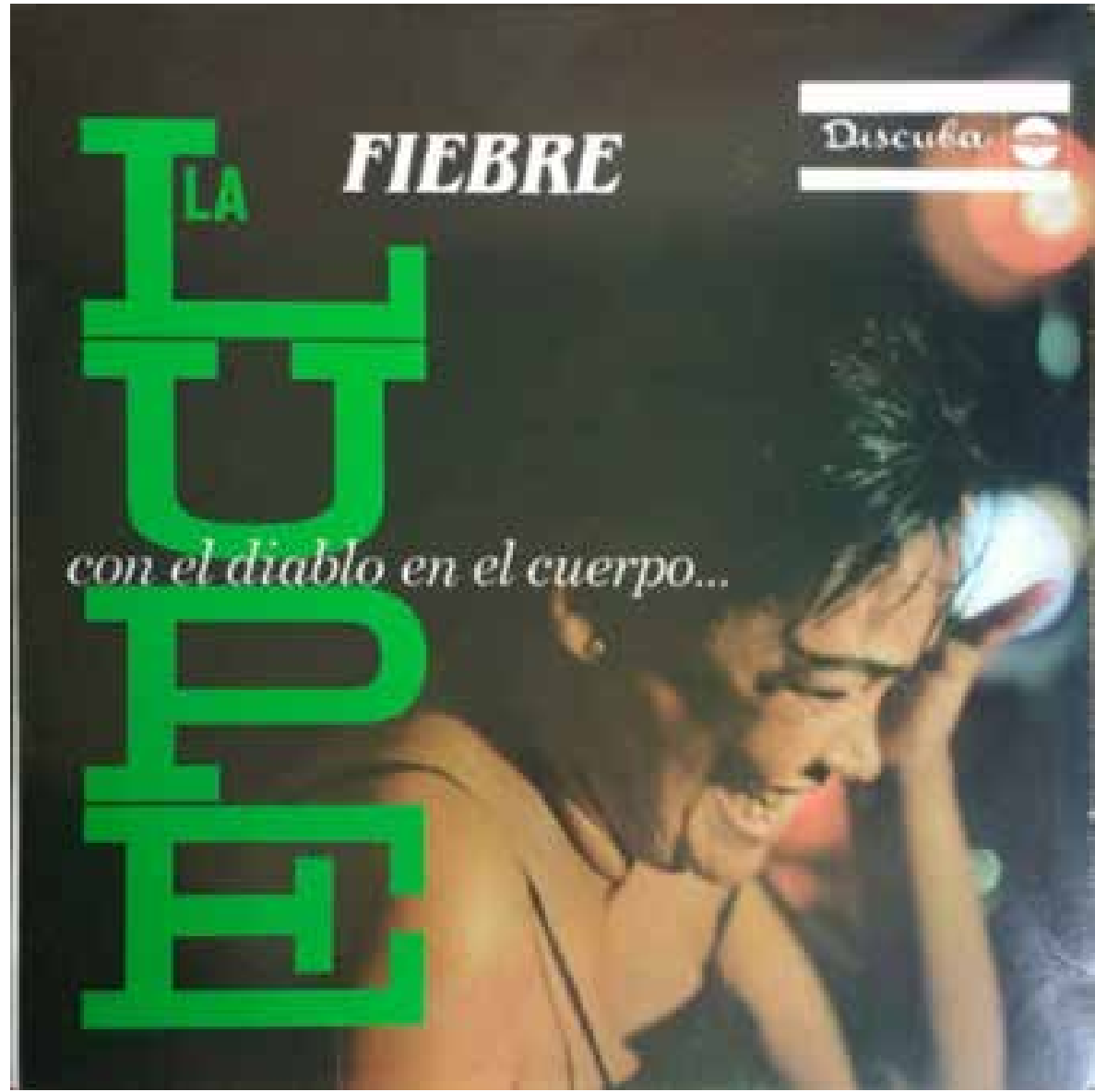

Imagen 2: La Lupe con el diablo en el cuerpo. Recuperada de https://www.discogs.com/

La-Lupe-Con-El-Diablo-En-El-Cuerpo/release/2943589

\section{III}

La Lupe no es solamente una intérprete porque, en este caso, raro y original, la pasión amorosa trasciende la escucha y se ubica en la materialidad del cuerpo. Cuando deseo y cuerpo se funden ${ }^{10}$ tiene lugar lo erótico y es en ese espacio en donde "aparece" La Lupe; ya no dentro de los estereotipos de sensualidad mediados por la Modernidad, primero, y por los medios masivos, después; sino a partir de la resignificación y de la ruptura con estos modelos. Dicha ruptura se establece en el espacio en donde se genera esa productividad erótica (shows televisivos, fotografías,

\footnotetext{
${ }^{10}$ En este caso "fundirse" no relaciona necesariamente la unión corporal. Según Dadoun (2006): “El erotismo encuentra su apuntalamiento, su fuente y sus recursos, su primordial sustancia y su objetivo dominante, reconocido o secreto, en la sexualidad. Pero al fundirse enteramente con ella, la desborda por completo, de modo que para darle una definición significativa se podría extender a todo cuanto, según unas modalidades y equilibrios culturales y personales de enorme variedad, descubre experiencias, expresiones y visiones carnales, existenciales, artísticas filosóficas, políticas" (p. 21).
} 
conciertos, entrevistas), en principio, a partir de dos aspectos. El primero de ellos, lo hemos denominado el autoestriptís; el segundo, la vitalidad real del erotismo.

En el primer caso, el autoestriptís ${ }^{11}$ es un espectáculo en el que el intercambio acostumbrado entre artista y espectador se pierde. Para ser más claros: en un espectáculo de estriptís, actor y espectador consienten en generar lo erótico. Así, el uno se despoja de "aquellas intervenciones que afectan al cuerpo" (Dadoun, 2006, p. 25) y el otro genera el deseo: el cuerpo del otro ha creado consciencia del propio cuerpo. El autoestriptís se regodea en el narcisismo, parece decir: para desear basta con un cuerpo, el propio. Actor-espectador maquina para su propia satisfacción. En su autoestriptís, La Lupe desgarra sus vestidos y juega a esconder sus muslos, arroja su joyería y usa su trasero como un instrumento más para apoyo de la orquesta. Pero a ese derroche nadie ha sido invitado. El espectador es un voyeur que apenas si satisface su deseo deseando ser el otro.

El segundo caso, la vitalidad erótica -que se encuentra en relación con el autoestriptís- despoja al erotismo de la domesticación que pide el espectáculo de la Modernidad de mediados del siglo XX en Latinoamérica y que se relaciona, como mencionamos anteriormente, con el papel pasivo de la mujer ante los ojos de quien la mira. La vitalidad erótica a la que nos referimos se muestra más bien como la resistencia del propio deseo ante las representaciones de un discurso romántico que se centra en la satisfacción del otro. No por casualidad, Jean Paul Sartre llamó a La Lupe "un animal musical". Su devenir animal encuentra en el cuerpo el lugar de expresión de un deseo mediante el canto y el baile.

El cuerpo erótico en La Lupe se presenta como una totalidad ofrecida al propio deseo, y también como fragmentación: morder sus manos, limpiar sus ojos y boca mientras canta, sujetar casi salvajemente su cabello, descalzar sus pies, arremangar los pantalones y dejar descubiertas sus pantorrillas... La escena se centra en su voz y baile, pero, además, en las partes de su cuerpo que quedan despojadas y visibilizadas, no como parte de un espectáculo histérico que busca la mirada del otro, sino más bien como un rito "instaurado en el seno de un 'dispositivo espectacular' que se caracteriza por un conjunto codificado de prácticas [...] y por un fuerte valor simbólico para sus actores y espectadores" (Pascal, 2015, p. 20), en el cual el vestido y los "buenos modos" interrumpirían el flujo vital del cuerpo.

${ }^{11}$ No antiestriptís, en el sentido que le da Dadoun (2006, pp. 24-25) pues, hablando de erotismo, el uso de la preposición "anti" haría referencia a lo domesticado y canalizado. 
En ese espacio, los ritos funcionan desde el propio cuerpo y la ofrenda obedece al deseo. De allí, que el acto ritual de La Lupe sea de carácter erótico: deseo, cuerpo y pasión son los elementos que lo conforman. Por supuesto que en la escena de La Lupe hay algo de "espectáculo, entonces, pero mucho más que esto el rito es una 'performance'” (Pascal, 2015, p. 21). No se trata del espectáculo preconcebido y ensayado de la actriz; es más bien uno que se establece a partir de hacer pasar por el cuerpo la sensorialidad que autogeneran la música y el canto. Es decir, la escena de La Lupe es una escena que afecta: "Es cierto que hay quienes dirían que la Yi Yi Yi -una de las cantantes más electrizantes que jamás hayan fulminado por el Planeta Tierra- era la pura encarnación del espíritu libre; y otros dirían que simplemente estaba poseída" (Suárez, 2015, párr. 1).

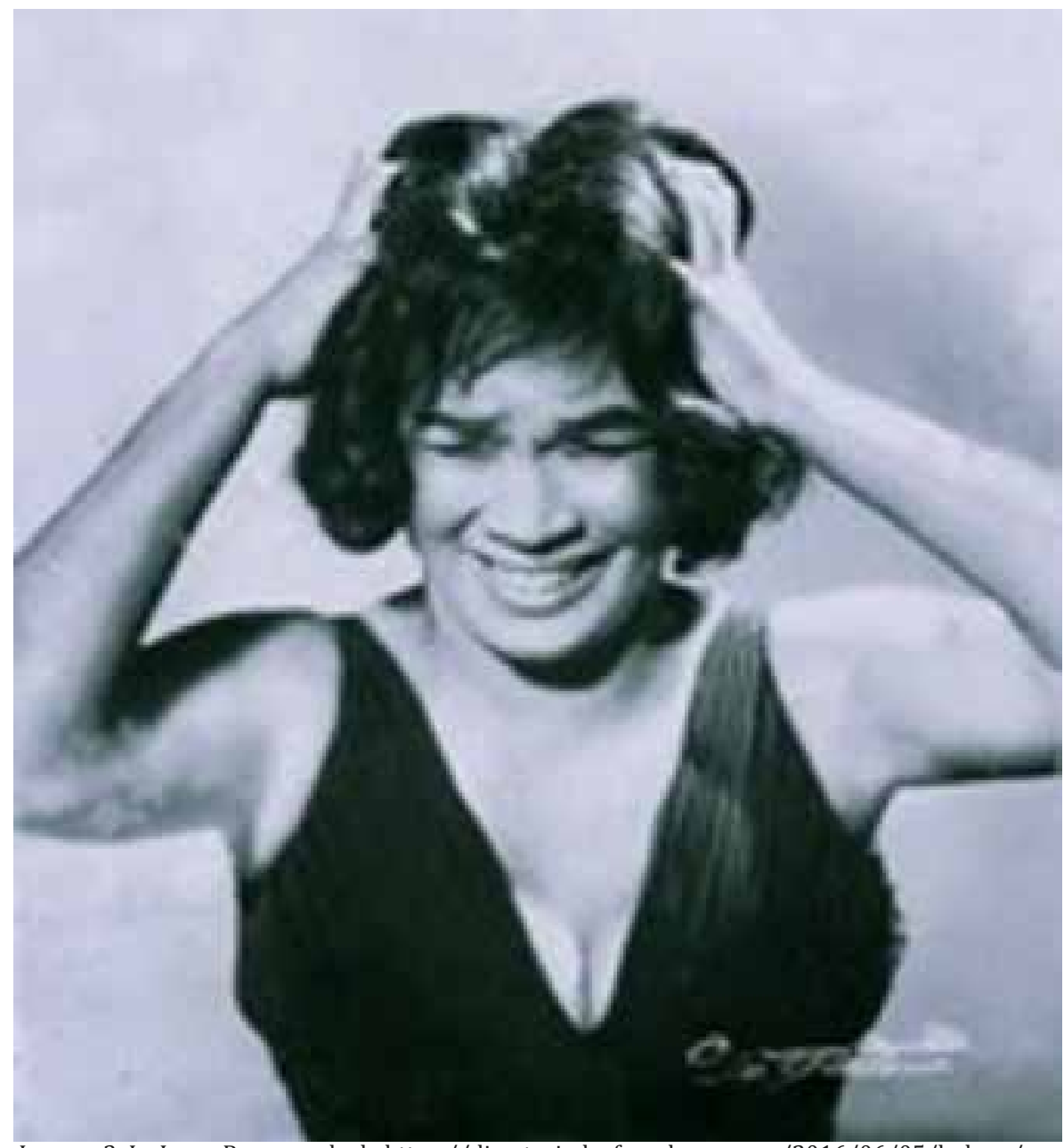

Imagen 3: La Lupe. Recuperada de https://directoriodeafrocubanas.com/2016/06/05/la-lupe/> 


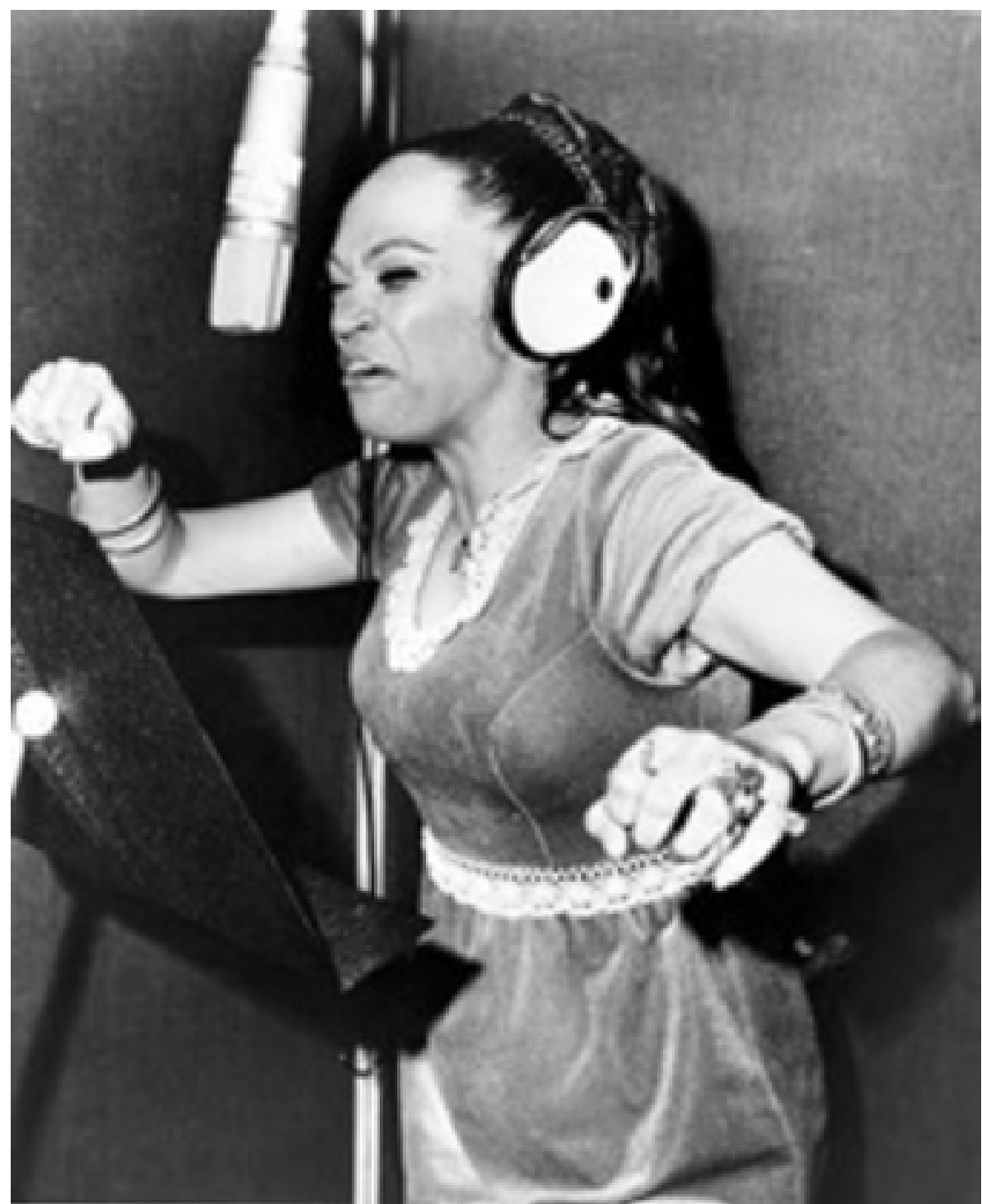

Imagen 4: Galería de imágenes de La Lupe. Recuperada de http://www.conexioncubana.net/ plugins/content/jw_sigpro/jw_sigpro/includes/download.php?file=images/la_lupe/La-Lupe025. jpg 


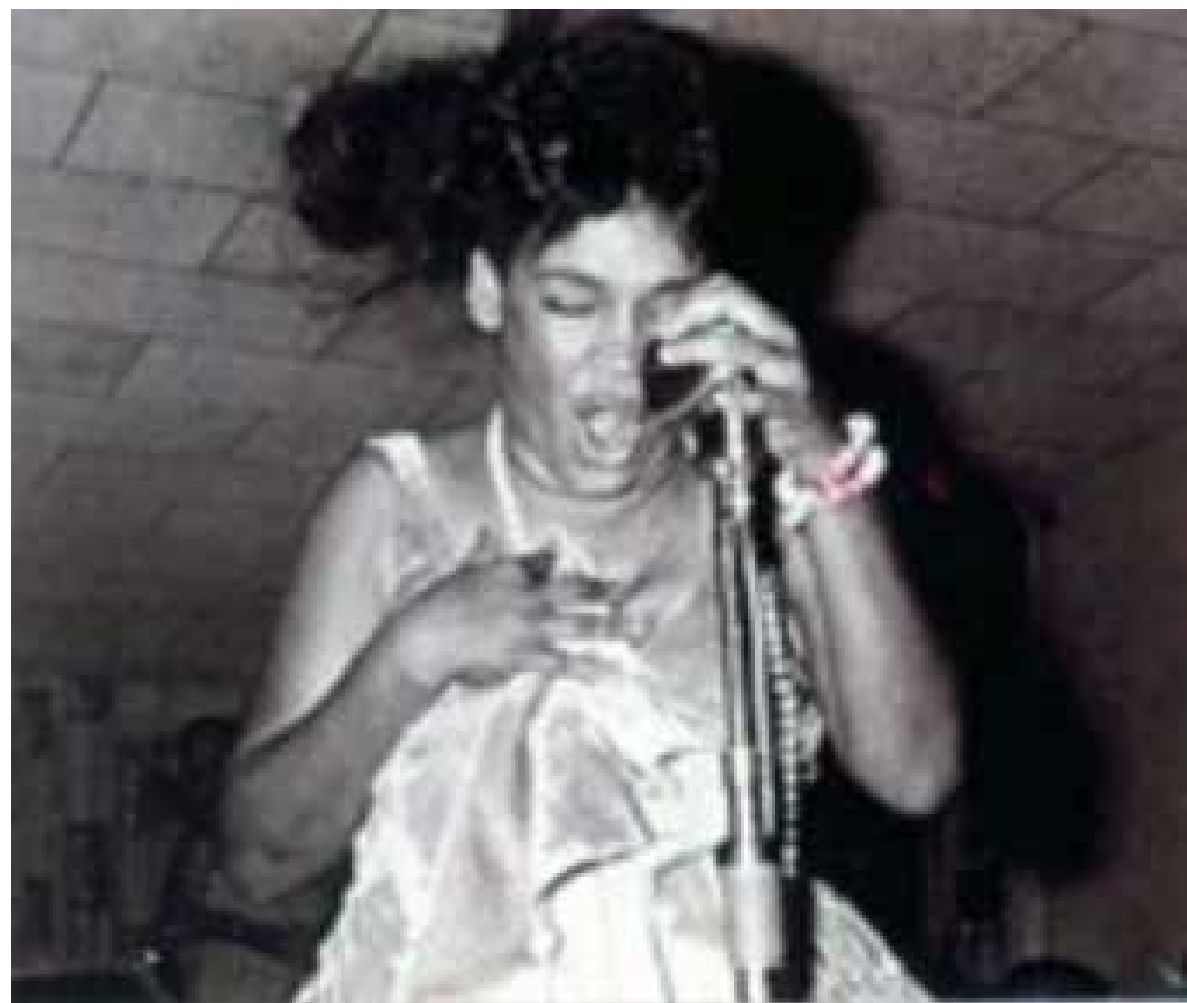

Imagen 5: Galería de imágenes de La Lupe. Recuperada de http://www.conexioncubana.net/ plugins/content/jw_sigpro/jw_sigpro/includes/download.php?file=images/la_lupe/La-Lupe015. jpg

Esos "arrebatos pasionales" que surgían en escena y que constituyen una de las principales marcas de la cantante, han encontrado en el discurso de la diva caribeña, tan sustentado por la prensa (Suárez, 2015), su relación con la santería; religión en la que el cuerpo, a través de su acción, es protagonista. Así, el baile a los santos no dejó de estar presente en conciertos como el de Central Park en la década de los 70. Tampoco la vestimenta blanca obligatoria para quienes se "hacen el santo". De manera que esa posesión de la que habla Suárez en su artículo de prensa podría asociarse con una escena del cuerpo que va más allá del trance de la santería. Se trata de la intervención de un cuerpo a partir de la música y el canto, y precisamente esta escena es la que pone en evidencia no tanto la anécdota de la creencia religiosa de La Lupe como la mirada estupefacta del otro ante la actuación de un cuerpo que se obedece a sí mismo. 


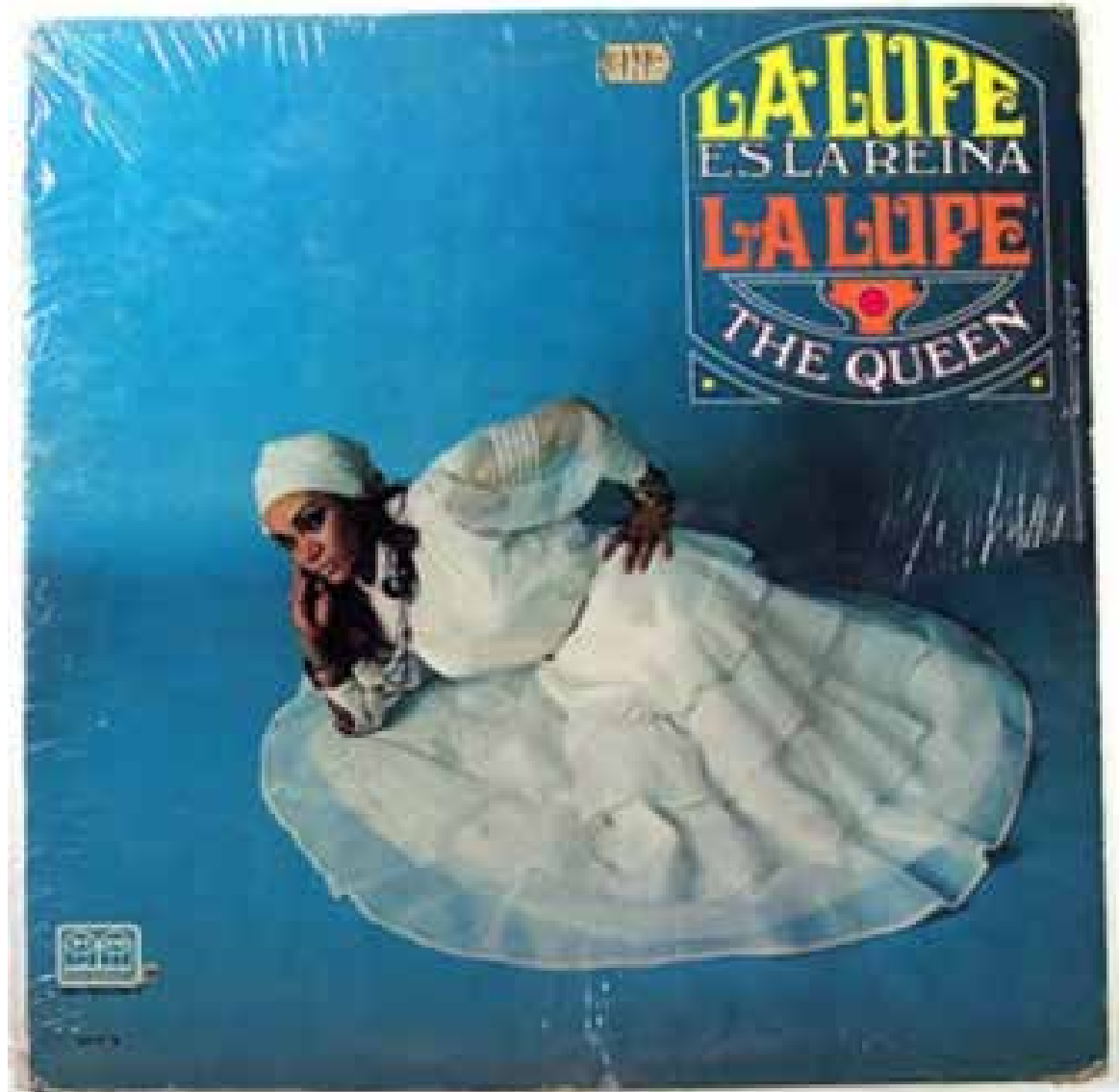

Imagen 6: La Lupe es la reina. Recuperada de https://www.discogs.com/La-Lupe-La-Lupe-Es-LaReina-La-<Lupe-The-Queen/master/566737

El desborde que habita el espacio erótico se derrama con toda su materialidad. Así, La Lupe no solo canta: grita y gime. Es decir, la melodía musical es atravesada por una sonoridad "que pone en juego el fundamento sensorial y las jerarquías del 'cuerpo' formado, instituido, por cierto tipo de historia ilustrada o moderna del pensamiento" (Ramos, 2010, p. 49). Gritos y gemidos en La Lupe remiten a la sexualidad, denotan un placer orgásmico que la ubica de nuevo en esa zona entre el personaje y la persona. No por lo que su anécdota de vida pudiera reflejarse en el discurso de diva caribeña, sino por lo que la vitalidad real del erotismo esparce en esa escena en donde ella, dueña de su deseo, se expresa a través del bolero, sobrepasando, completando y/o excediendo el discurso amoroso de este género.

\section{IV}

Queda clara la estrecha relación entre La Lupe y el erotismo. Decadente o sex simbol, hay un cuerpo que bulle, un fuego que atraviesa cualquier 
vestidura. Es la mujer que muestra aquello que nadie puede poseer. Se expresa salvajemente, pero es ajena, solo suya. El escenario ilumina al monstruo y al enigma. "Nadie la conoce. Solo la ven”, diría un lánguido Spencer Tracy embobado por una vedette en medio de la selva. ${ }^{12} \mathrm{Y}$ es allí, en el enigma, que La Lupe se ubica como personalidad excepción en el sentido de "personalidades emergentes en las que se reconocen otras voces, otros discursos, otras puestas en escena" (Campos, 2016, p. 16).

En el plano musical, La Lupe se inscribe en el bolero a través de una marca que la deja en ese lugar entre del canon. Voz, gritos, gemidos y la escena en la que el cuerpo es protagonista son los elementos que, por una parte, la ubican como una "Original" en la historia musical del Caribe y que, por otra, la arrojan a los márgenes de esta. Nadie como ella supo llevar con tanta naturalidad una carga tal de contextos. La misma noción de enigma ubica a La Lupe dentro de lo erótico. En el escenario hay un acto de autoestriptís que cuestiona y lo confirma. Respecto del discurso generado no hay certezas, sino la construcción de un personaje ante el vacío de la historia "verdadera". Lo que resulta excitante en La Lupe es la expectación de su escena, la espera del escucha-amante-espectador ante su aparición.

Esa originalidad de La Lupe, que la convierte en personalidad de excepción, abarca el problema del cuerpo en múltiples aspectos, siendo la música, y específicamente el bolero, el núcleo desde donde se esparcen elementos, en ocasiones, inarticulables dentro de la industria del entretenimiento o la cultura en general, porque es la vitalidad real de su erotismo la que establece la relación entre vida-obra que también caracteriza la personalidad de excepción dentro de un momento en el que el discurso del bolero aún daba claves al imaginario popular latinoamericano. De manera que dentro de este discurso y también dentro del canon del bolero, La Lupe se inscribe como un exceso.

Es este exceso el que genera una productividad que la ubica más allá de su contexto y tiempo histórico, en una permanente actualización. De allí, las numerosas producciones que tratan de asirla -con cierta manipulación de la anécdota de su vida-, e intentan atraparla como si de un personaje de ficción se tratara. Más allá de las especulaciones, los homenajes y las representaciones ficcionales, la productividad de La Lupe radica en el hecho de que como señalara Michel Foucault (1999) respecto del autor en la escritura, abre un espacio en el que "el sujeto no deja de desaparecer" (p.

${ }^{12}$ Malaya (1949), tragedia sudorosa del director Richar Thorpe en el que se implica también a James Stewart. 
81). No se trata entonces de una "puesta en escena", sino de una estrecha relación entre vida-obra que no cesa de generar vitalidad. Se trata de la confirmación de una "ética, de una forma-de-vida" (Cróquer, 2012, p. 88), que más allá del discurso sobre el personaje, nos permite seguir pensando este enigma, ahora como artefacto cultural. 


\section{Bibliografía}

»Campos, D. (2016). Las trampas de la escritura. Panteón de poetisas latinoamericanas: Caso Alfonsina Storni. Tesis de Maestría inédita. Mérida, Venezuela: Universidad de los Andes.

» Castillo Zapata, R. (1990). Fenomenología del bolero. Caracas: Monte Ávila.

"Cróquer, E. (2012). Casos de autor: anormales/originales de la literatura y el arte (II). Allí donde la vida (es) obra. Voz y escritura. Revista de estudios literarios, 20, 89-103.

»Dadoun, R. (2006). El erotismo. Madrid: Biblioteca Nueva.

»Deleuze, G. (2009). Bartebly o la fórmula. Preferiría no hacerlo (pp. 57 92). Recuperado de https://es.scribd.com/document/153657099/GillesDeleuze-Bartleby-o-la-Formula

»Foucault, M. (1999). ¿Qué es un autor? Litoral, 9(83, junio 83), 51-82.

»Isava, L. (2009). Breve introducción a los artefactos culturales. Estudios, 17(34), 441-454.

» Kristeva, J. (1970). La productividad llamada texto. Lo verosímil (pp. 63-93). Buenos Aires: Tiempo contemporáneo.

»Karmer, J. (Ed.). (2007). La Lupe Queen Of Latin Soul. New York: Troyano Inc. Recuperado de https://www.youtube.com/watch?v=UB_ bIHCbeC8\&feature=youtu.be

" La Lupe cuenta su vida y "conversión". (2013). Video recuperado de https:// www.youtube.com/watch?v=uhGQNQ5Kwl4

" Lara, G. (2001). Bolero: amor, texto y cultura. Islas, 43(20), 20-38.

"Martín Barbero, J. (1991). De los medios a las mediaciones. Comunicación, cultura y hegemonía. México: Editorial Gustavo Gilli.

» Montaldo, G. (2001). Teoría crítica, teoría cultural. Caracas: Equinoccio.

»Pascal, L. (2015). ¿Ritualidad versus modernidad...? Ritos, identidad cultural y globalización". Revista MAD, 33, 18-28.

» Posada, J. (2016). La Lupe, víctima de una mala biografía. El Nuevo Herlad (03 de marzo de 2016). Recuperado de https://www.elnuevoherald.com/ entretenimiento/musica/article63891827.html

» Ramos, J. (2010). Descarga acústica. Papel máquina. Revista de cultura, 2(4), 49-77.

»Suárez, M. (2015). La Lupe, puro teatro. Diario de Cuba (Madrid 31 de agosto). Recuperado de https://www.gabitos.com/Cuba_Eterna/template. php?nm=1502893382

» Zavala, I. (1995). El bolero: el canto del deseo. Anthropos,166/167, 104-108. 


\section{Biografías / Biografias / Biographies}

\section{Celiner de Jesús Ascanio Barrios}

Candidata a Doctora del Programa de Literatura Latinoamericana de la Universidad Andina Simón Bolívar, sede Ecuador (2015-2020), Magíster en Literatura Latinoamericana por la Universidad Simón Bolívar de Venezuela (2012) y Licenciada en Letras por Universidad Central de Venezuela (2001). Desde 2005 ha sido profesora del área de Lenguaje en Venezuela y Ecuador. Es integrante del Centro de Investigaciones Críticas y Socioculturales de la Universidad Simón Bolívar, Venezuela (http://www.cics-usb. org/). Las líneas a partir de las cuales ha desarrollado su investigación son: Representaciones de la delincuencia en Venezuela, Políticas del discurso en Venezuela y Escritura y alteridad, sobre las cuales ha publicado diversos artículos y el libro Cuerpos y voces de la transición. Representaciones del delincuente en la narrativa venezolana (2018). Actualmente desarrolla su investigación doctoral sobre arte, escritura y delirio.

\section{Christian Paul Chasi Escobar}

Magíster en Estudios de la Cultura, mención Literatura Latinoamericana por la Universidad Andina Simón Bolívar, sede Ecuador (2014). Desde 2013 ha sido profesor universitario del área de Lenguaje en Ecuador. La línea a partir de la cual ha desarrollado su investigación es Tradición oral afroecuatoriana. Su trabajo de grado "El Riviel", leyenda oral afroecuatoriana o de cómo la memoria tornó en azul obtuvo mención honorífica y mención publicación. 